\title{
Evaluation of Factors Affecting Student Participation in Peer-Assisted English Learning Based on Online Education Platform
}

\author{
https://doi.org/10.3991/ijet.v16i11.23319
}

\author{
Hong Hu, Xiuli Wang, Yuhui Zhai \\ Anhui Jianzhu University, Hefei, China \\ Jian $\mathrm{Hu}^{(\triangle)}$ \\ Anhui University, Hefei, China \\ hujianpost@126.com
}

\begin{abstract}
Through a questionnaire survey, this study explored the factors affecting student participation in peer-assisted English learning (PAEL) based on online education platforms. Specifically, the authors constructed the system of PAEL contents, analyzed the online PAEL behaviors of students, and evaluated the student participation in online PAEL from both surface participation and deep participation. On this basis, the influencing factors of student participation in online PAEL were evaluated thoroughly. In the end, several countermeasures were presented to solve the problems with student participation in online PAEL. The results show that: the online PAEL face such problems like low-level knowledge structure and poor interaction quality, weak intensity of interaction, and inactive atmosphere of collaboration; In general, the students are not actively participating in online PAEL; the student participation in online PAEL is greatly affected by teachers, students, teaching contents, and online education platforms; the low participation in online PAEL mainly arises from the weak motives of students for online PAEL, the inadequate teaching design and supervision of teachers, and the imperfect functions of online education platform. The research enriches the theoretical and practical results on the factors affecting student participation in online PAEL.
\end{abstract}

Keywords - Online education platform, peer-assisted English learning (PAEL), interaction behavior, influencing factors of participation

\section{Introduction}

The popularization and application of Internet technology has greatly changed people's learning methods, breaking the limitations of time and space of traditional teaching method, now students can learn according to their own needs anytime and anywhere [1], and online education platforms are providing an excellent environment for teacher-student exchanges [2]. Especially in recent years, colleges and universities 
have gradually realized the importance of online teaching, and they have established various online education platforms successively.

Student participation is a necessary condition for online learning, the degree of participation directly determines the teaching effect of online learning [3]. Peer-assisted learning is a learning method with the interaction between peers as its core content, in an online learning environment, the quality and features of such interactive behavior between learners have a direct impact on learners' learning efficiency and their enthusiasm to participate in online learning [4]. In view of this matter, scholars at home and abroad have conducted researches on student participation and peer-assisted learning in the context of online learning, and have achieved fruitful results. In terms of online learning participation, scholars have analyzed from the aspects of the concept of student participation in online learning, the online learning participation behavior, the influencing factors of student online learning, and the promotion strategies for online learning participation of college students [5]. In terms of peer-assisted learning, scholars have studied from the aspects of the theories of peer-assisted learning, the patterns and strategies of peer-assisted learning, and the application of peer-assisted learning, etc. [6]. After reviewing related reference literatures, it's found that current research on the influencing factors of student participation in peer-assisted learning based on online learning is insufficient [7]. Therefore, based on the above analysis, this paper attempts to analyze and study the influencing factors of student participation in online PAEL based on online education platforms.

\section{Interactive Behavior of Students' Online PAEL Based on Online Education Platforms}

\subsection{Construction of the interactive content system of PAEL}

The determination of interactive content of students' online PAEL is the core content for the analysis on the interactive behavior of students' online PAEL [8]. Therefore, from the perspectives of learning community and knowledge construction, this paper constructed the interactive content system of PAEL [9], as shown in Figure 1.

\subsection{The interactive behavior analysis of PAEL}

145 students from 3 classes of non-English majors in a university were chosen as the research objects to conduct interactive behavior analysis on students' online PAEL. According to the interactive content system of PAEL established above, the contents of online posts generated during students' online PAEL were collected, classified, and converted to analyze students' interactive behavior during online PAEL [10]. 


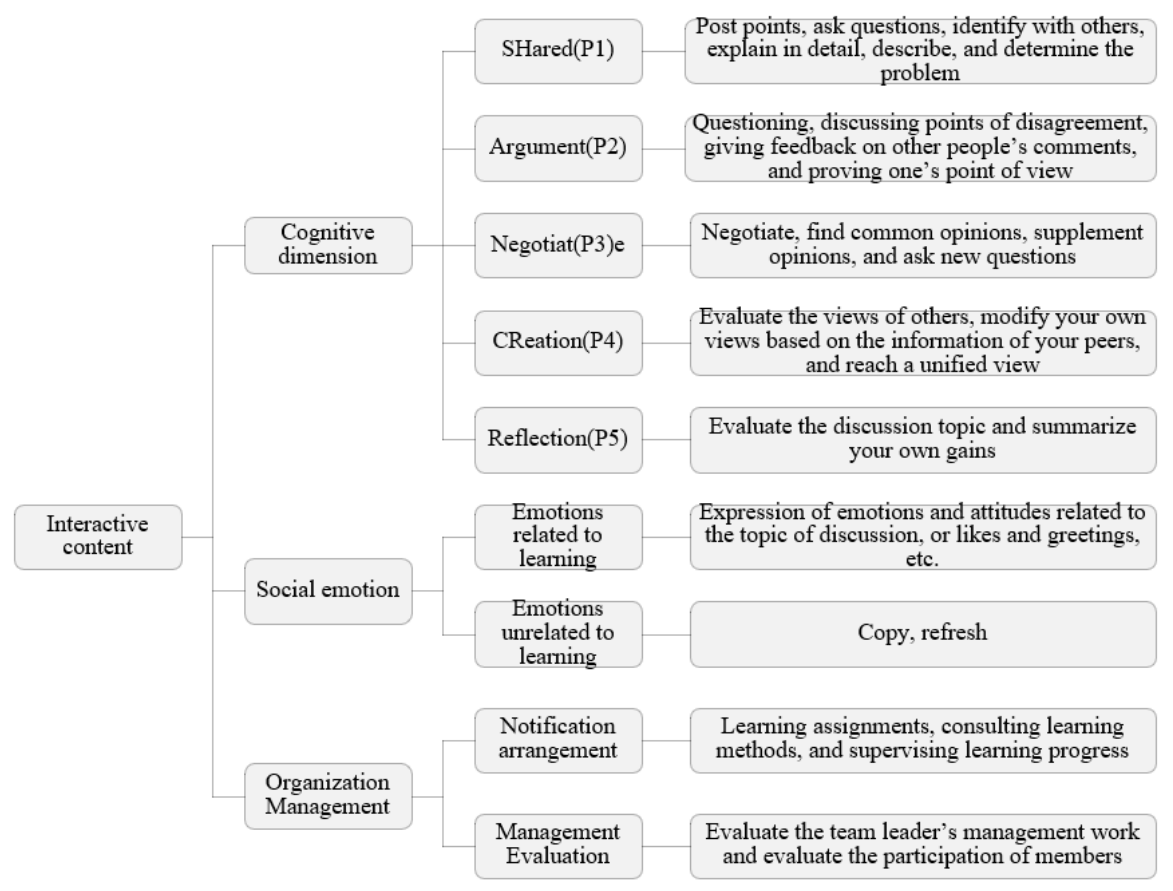

Fig. 1. Interactive content system

Table 1. Percentage of various posts

\begin{tabular}{|l|c|}
\hline \multicolumn{1}{|c|}{ Release Type of posts } & Percentage \\
\hline Ask a question or start a topic & $21 \%$ \\
\hline Answer the questions & $14 \%$ \\
\hline Data sharing & $5 \%$ \\
\hline Agree or question & $7 \%$ \\
\hline Summary of Views & $7 \%$ \\
\hline Opinion evaluation & $13 \%$ \\
\hline Reflection on learning & $3 \%$ \\
\hline Emotional & $23 \%$ \\
\hline Nothing to do with learning and discussion content & $8 \%$ \\
\hline
\end{tabular}

\section{Overall content analysis}

Table 1 shows the statistics of the percentages of various types of posts about PAEL topics posted by students on online education platforms. According to statistics, the top 3 were emotional posts, posts for asking questions or starting topics, and posts for answering questions, accounting for $23 \%, 21 \%$ and $14 \%$ respectively. Emotional posts are mostly good-hearted emotional output, the post contents are usually evaluations, encouragement, and affirmation given by students to their peers or team leaders for their PAEL; although these posts are not that related to the learning content, they can promote emotional communication and exchanges between peers, and they are helpful for PAEL. Posting for asking questions or starting topics are mostly 
about the problems encountered by students during English learning, and they post them to seek answers from their peers, such as the rules of English grammar, the differences in sentence patterns, etc., this is the basic stage of the cognitive development of learners and the foundation of students' PAEL in subsequent stage. Compared with the posts of raising questions and initiating topics, the number of posts answering questions is much less, only accounting for 14\%, indicating that students' PAEL is in a poor mutual beneficial status, during interactive activities, most students are in a "receiving" status without "output". According to the statistics, the bottom 4 were learning reflection posts (3\%), information sharing posts $(5 \%)$, agreements or doubts $(7 \%)$, and opinion summary (7\%), indicating that only a small number of students can summarize and reflect on the knowledge they learnt and sublimate the knowledge to another level, most of them lack independent thinking when studying, and they are used to follow the herd. In addition, posts unrelated to learning and topic discussion accounted for $8 \%$, indicating that students' PAEL lacks effective teaching organization and management.

\section{Cognitive and interactive behavior analysis}

The learner's cognitive and interactive behaviors have an important impact on their knowledge structure construction. To further explore the interactive behaviors among students during online PAEL and understand the interaction quality of learners, this paper analyzed the conversions between learner behaviors from the cognition and interaction aspect with the largest number of student posts. Table 2 shows the frequency and score statistics of learners' behavior sequences. Rows in the table represent the initial behavior, and the columns represent the subsequent behavior. For example, P2P4 represents that a student performs creation behavior immediately after the demonstration behavior. SPSS was used to convert the behavior frequency to Zscore to obtain the learner behavior scores [11].

Table 2. Learner behavior sequence frequency and score statistics table

\begin{tabular}{|c|c|c|c|c|c|c|}
\hline \multirow{2}{*}{ Interactive behavior } & \multicolumn{2}{|l|}{ P1 } & \multicolumn{2}{|l|}{$\mathbf{P 2}$} & & \\
\hline & Frequency & Score & Frequency & Score & & \\
\hline $\mathrm{P} 1$ & 85 & 2.18 & 2 & -0.71 & & \\
\hline $\mathrm{P} 2$ & 82 & 1.99 & 1 & -0.68 & & \\
\hline P3 & 19 & -0.04 & 2 & -0.70 & & \\
\hline $\mathrm{P} 4$ & 15 & -0.24 & 23 & 0.02 & & \\
\hline $\mathrm{P} 5$ & 1 & -0.7 & 5 & -0.53 & & \\
\hline \multirow{2}{*}{ Interactive behavior } & \multicolumn{2}{|l|}{ P3 } & \multicolumn{2}{|l|}{ P4 } & \multicolumn{2}{|l|}{ P5 } \\
\hline & Frequency & Score & Frequency & Score & Frequency & Score \\
\hline $\mathrm{P} 1$ & 86 & 2.15 & 39 & 0.66 & 2 & -0.71 \\
\hline $\mathrm{P} 2$ & 6 & -0.56 & 8 & -0.50 & 1 & -0.68 \\
\hline $\mathrm{P} 3$ & 15 & -0.17 & 13 & -0.33 & 2 & -0.70 \\
\hline $\mathrm{P} 4$ & 14 & -0.29 & 89 & 2.25 & 23 & 0.02 \\
\hline $\mathrm{P} 5$ & 1 & -0.70 & 12 & -0.36 & 5 & -0.53 \\
\hline
\end{tabular}

Note: Only when Z>1.96, the frequency of a behavior sequence is statistically significant. 
According to the table, among the learning behavior sequences, only four reached the significant level, namely P1-P1, P1-P2, P3-P1, and P4-P4, indicating that the students' cognition structures during PAEL were mostly at the first, third, and fourth stages; the learning behavior sequences did not proceed according to the cognitive level from low to high, and this means that the students' overall knowledge structure is at a relatively low level.

\section{Problems in the interactive behavior of students' online PAEL}

The above analysis results suggest that there're a few problems with students' online PAEL: first, the low-level knowledge structure and poor interaction quality of learners, specific manifestations are: the dialogue between peers is superficial and of low reciprocity level (less mutually beneficial), the dialog content is random and discrete, and the individual behavior is irregular; second, weak interaction intensity of learners, and inactive atmosphere of collaboration, specific manifestations are: the interaction between students lacks effective replies, and it's in short of effective instructions from teachers and administrators.

\section{Influencing Factors of Student Participation in PAEL Based on Online Education Platform and the Evaluation}

Analysis suggests that there are still many problems with students' PAEL based on online education platforms. In order to improve the efficiency of online PAEL, combining with relevant reference literatures, this paper gave an overall evaluation to students' online PAEL from two aspects of surface participation and deep participation [12]. Then by conducting questionnaire survey and interviews, the influencing factors of student participation in PAEL based on online education platforms were further analyzed and evaluated.

\subsection{Surface participation and evaluation indicators}

Surface participation refers to the explicit learning behaviors of students during their online learning process recorded by the management system of online education platforms [13], such as the time spent on watching videos, and the status of homework completion, etc. By analyzing students' online learning data, this paper determined three evaluation indicators for the surface participation of students, namely clickbrowse, create-reply, and complete-submit; under each evaluation indicator, there're several second-level evaluation indicators, as shown in Figure 2. By sorting out the platform data and calculating one by one according to the corresponding standards, the evaluation indicators of both levels were eventually shown in a hundred-mark system. 


\subsection{Deep participation and evaluation indicators}

From the two aspects of homework correct rate and post content quality, this paper determined the evaluation indicators for the deep participation of students, then, based on whether an indicator can be directly measured or not, the evaluation indicators were divided into two kinds: direction measurement and indirect measurement, as shown in Figure 3; then, standard reference measurement methods were adopted for the statistical analysis of relevant data [14].

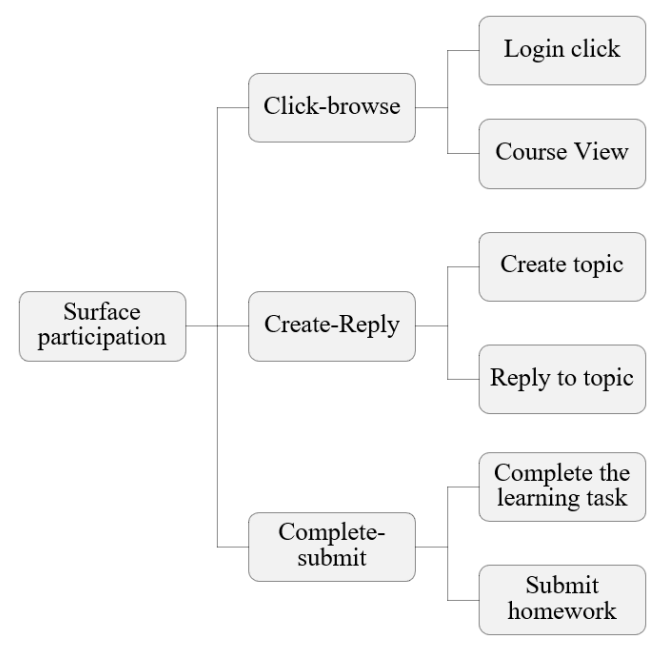

Fig. 2. Evaluation indicators of surface participation

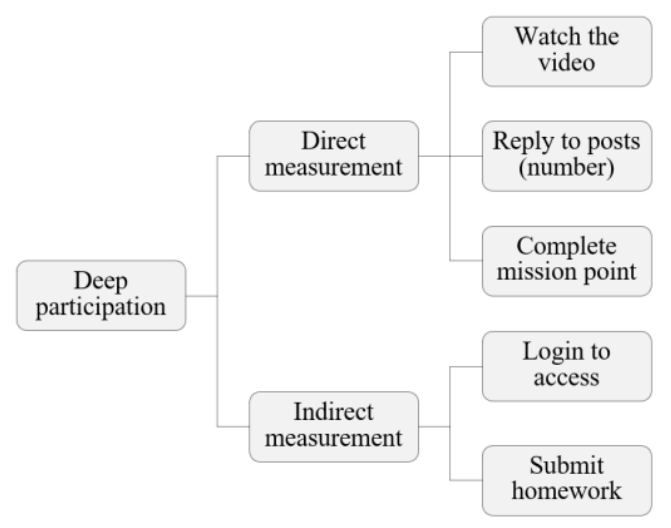

Fig. 3. Evaluation indicators of deep participation

\subsection{Overall evaluation of students' participation in online PAEL}

Figure 4 shows the statistical results of students' participation in online PAEL, it can be seen from the figure that the data exhibit a high degree of dispersion. For the 
degree of participation of students in online PAEL, the highest score was 88 points, the lowest score was 2 points, the average score was 62 points, and the standard deviation was 14 , indicating that the overall situation of student participation in online PAEL was not good.

In order to further figure out the participation status of students in online PAEL, this paper analyzed the current status of students' surface participation and deep participation in PAEL, and the results are shown in Figure 5. According to the figure, we can see that the data of participation degree showed high-degree dispersion and large fluctuations, indicating that the situation of students' surface participation and deep participation was not good.

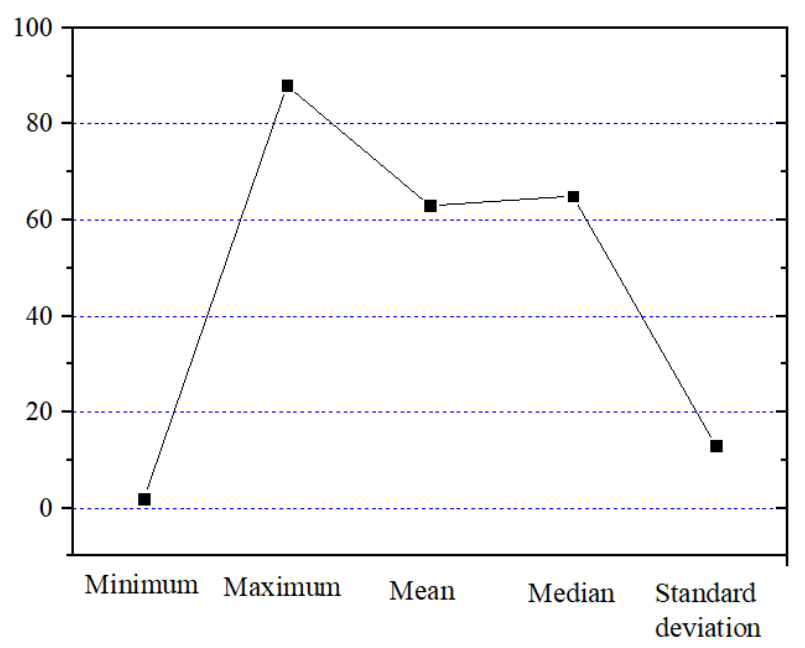

Fig. 4. Statistical results of students' participation in online PAEL

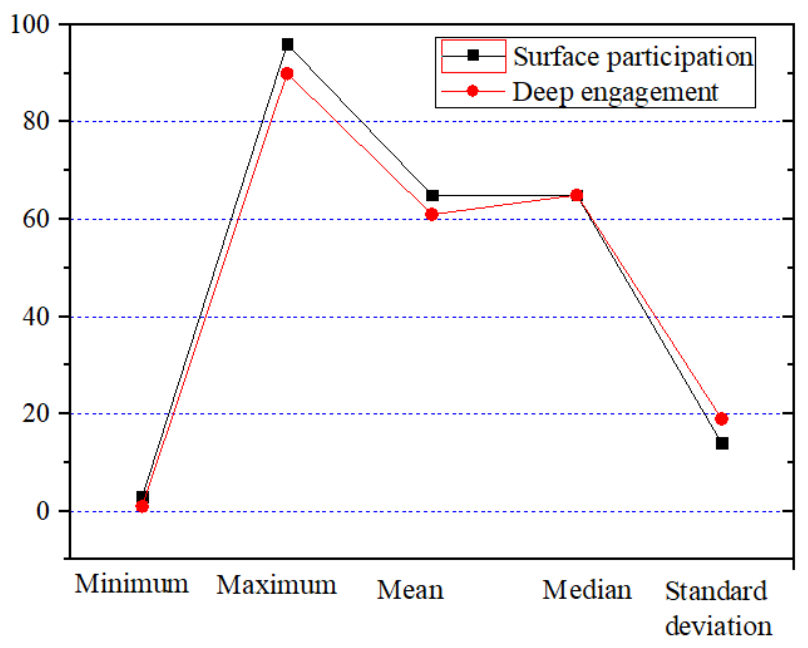

Fig. 5. Current status of students' surface participation and deep participation in PAEL 


\subsection{Investigation on the influencing factors of student participation in PAEL}

1. Statistics of students' participation in PAEL

Still, the 145 students from 3 classes of non-English majors in a university were taken as the research objects. After reviewing relevant domestic and foreign documents, the Questionnaire for Investigating Influencing Factors of Student Participation in Online PAEL [15] was designed. A total of 145 questionnaires were distributed, 132 valid questionnaires were returned, the effective rate was $91.03 \%$. Then the questionnaires were sorted out to analyze the influencing factors of student participation in online PAEL.

Figure 6 shows the survey results of students' willingness to participate in online PAEL. The students who are reluctant and very reluctant to participate in online PAEL accounted for $1.6 \%$ and $13.7 \%$, respectively. Students who participate in PAEL as required accounted for the highest proportion of $59.4 \%$, which is more than half of the total, indicating that most students do not participate in PAEL out of their own willingness or learning needs, they just complete them as learning tasks per the teachers' requests.

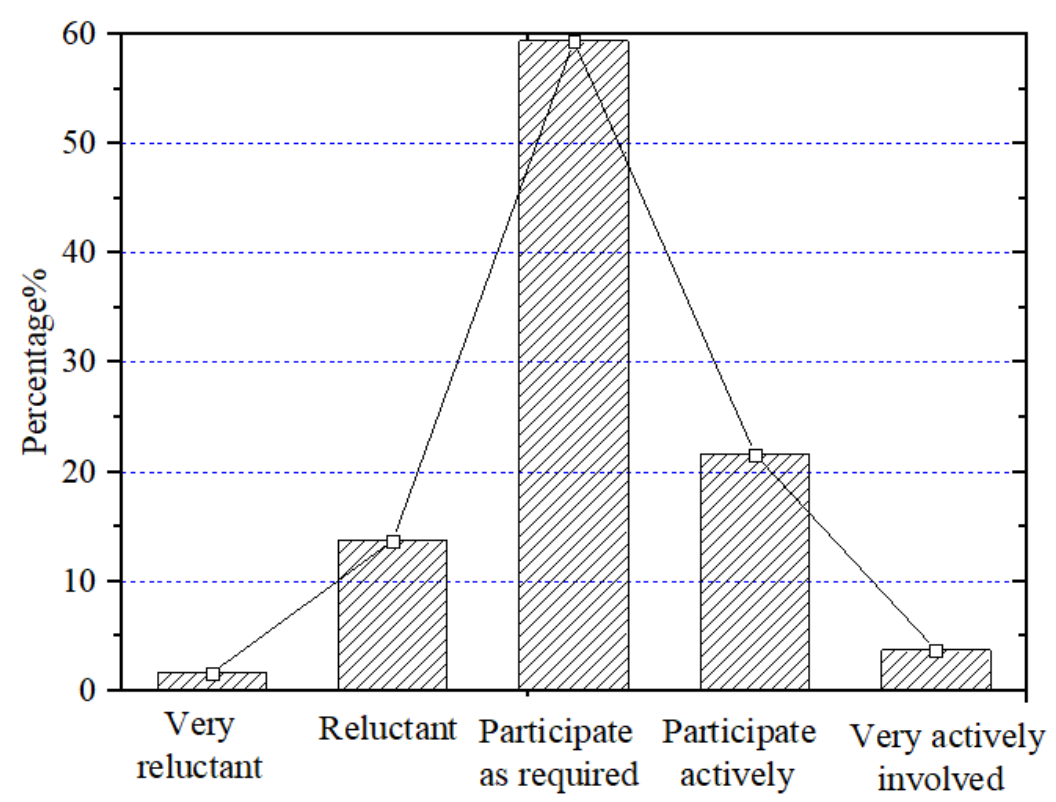

Fig. 6. Students' willingness to participate in online PAEL 


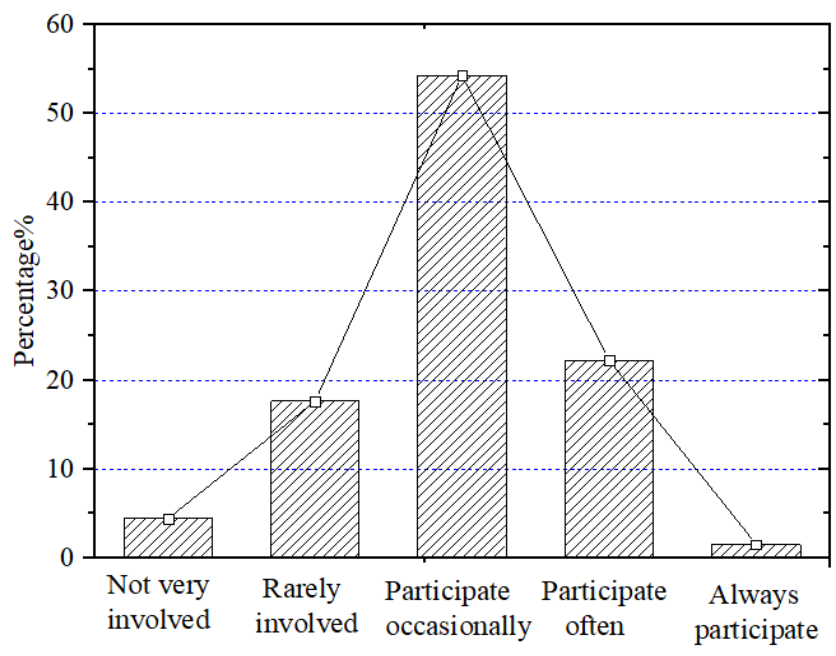

Fig. 7. Students' descriptions of their participation in PAEL

Figure 7 gives respondent students' descriptions of their participation in online PAEL, according to the figure, students who are not involved in or rarely involved in PAEL accounted for $22 \%$ of the total number; students who always participate in or often participate in PAEL accounted for $1.5 \%$ and $22.2 \%$ respectively, indicating that the situation of students' participation in online PAEL is not optimistic.

Figure 8 shows the survey results of students' satisfaction with online PAEL, it can be seen from the figure that students who chose "not so satisfied" accounted for $34.4 \%$ of the total number, and those who are satisfied and quite satisfied accounted for $37.5 \%$ and $20.8 \%$, respectively, indicating that although most students are satisfied with their online PAEL results, still, some students are not that satisfied.

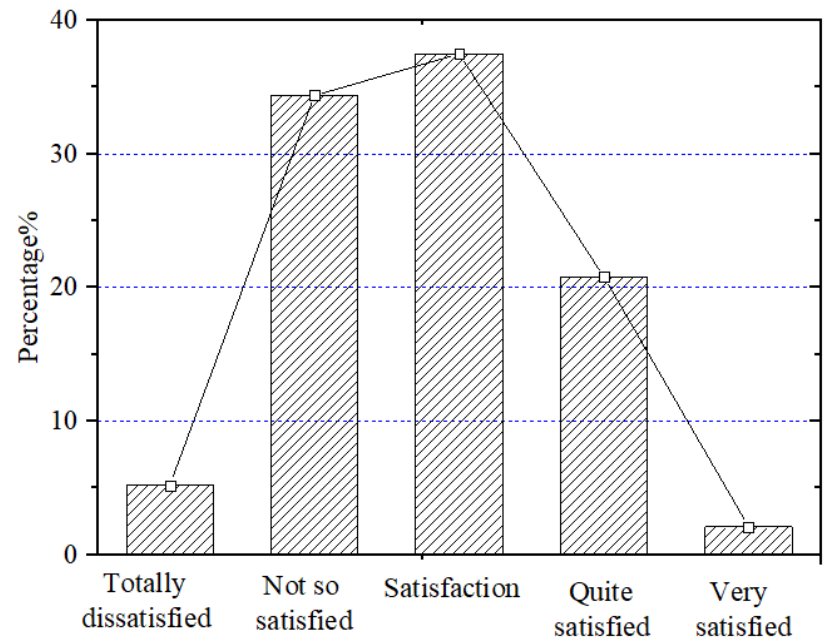

Fig. 8. Students' satisfaction with online PAEL 
2. Analysis of influencing factors of student participation in online PAEL

\section{i. Teacher factors}

Figure 9 gives the statistics of students' perceptions of the influence of teachers on student participation in online PAEL, we can see from the figure that among the several teacher factors, three factors have greater influence on student participation in PAEL, namely: whether teachers provide guidance and help for PAEL; whether teachers assign online learning tasks; whether teachers guide and encourage online PAEL. As for other teacher factors, the percentages of students who believed these factors also have an impact on PAEL were all above $40 \%$. Therefore, this indicates that the teachers' influence on student participation in online PAEL is non-ignorable.

\section{ii. Student factors}

Figure 10 gives the statistics of the percentages of students choosing agree with the 6 questions about PAEL participation, the data suggests that more than half of the students agreed that "having positive expectations for online learning tasks" and "the selection and application of learning methods" have great influence on their participation in PAEL; except for the question of "are you interested", as for the other questions, the percentages of students who agreed these factors have an impact on PAEL were all above $45 \%$, indicating that students themselves have a great influence on their participation in online PAEL.

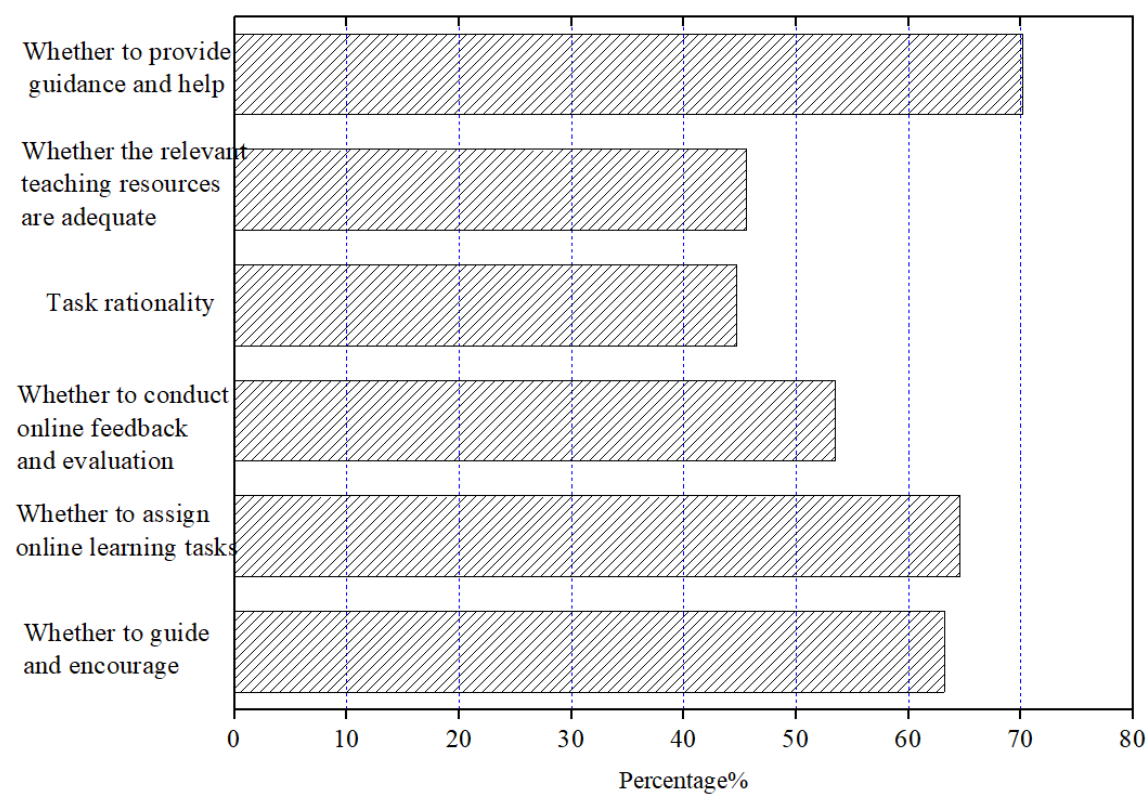

Fig. 9. Influence of teacher factors on student participation in online PAEL 


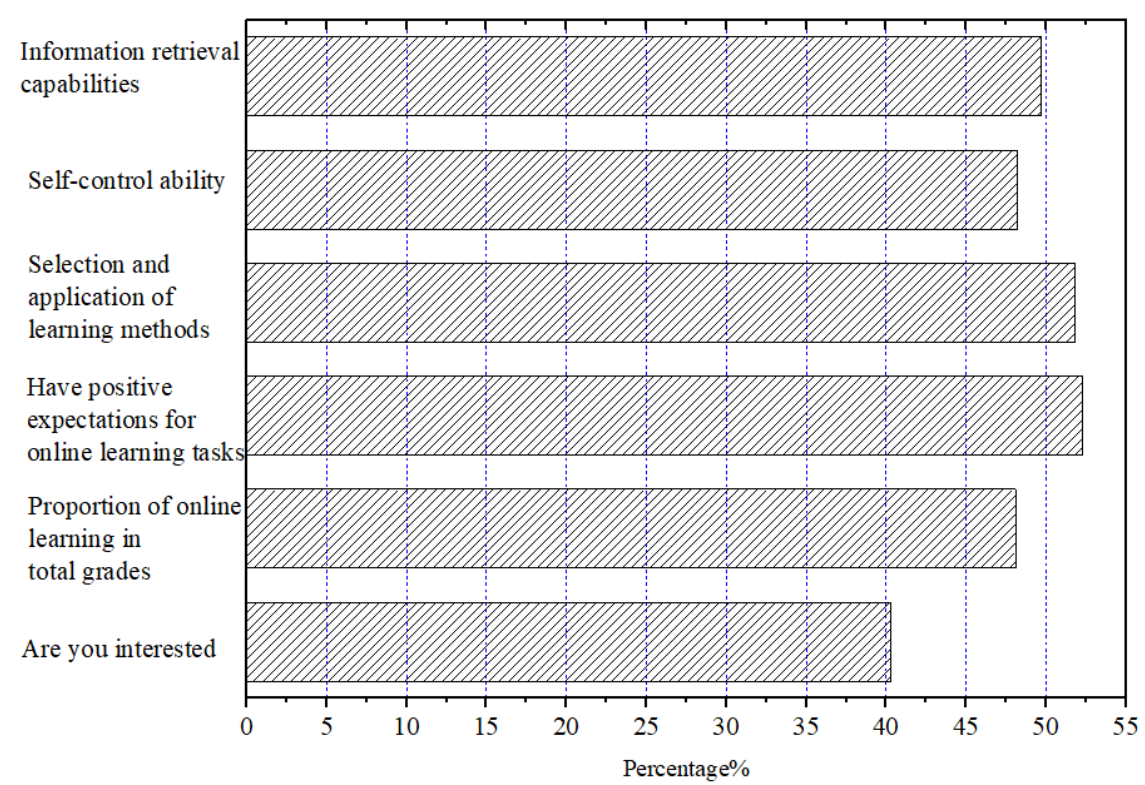

Fig. 10. Influence of student factors on student participation in online PAEL

\section{iii. Teaching content factors}

Figure 11 shows the survey results of the influence of teaching content on student participation in online PAEL. Statistical data tells us that the two most influential teaching content factors for student participation in online PAEL are "types of questions for online assignments" and "peer communication and feedback"; except for the two factors of "clear teaching objectives and content" and "online and offline teaching content consistency", for the other factors, the percentages of students who agreed these factors have an impact on PAEL were all above $45 \%$, indicating that the teaching content does have a great impact on student participation in online PAEL.

iv. Online education platform factors

Figure 12 shows the survey results of the influence of online education platform on student participation in online PAEL. From the figure we can read that students believe the resource compatibility has the greatest impact, followed by the "interesting and interactive learning resources" and "resource update range and frequency". Except for the factor "time and space convenience of platform use", for the other factors, the percentages of students who agreed these factors have an impact on PAEL were all above $45 \%$, indicating that the online education platforms also have a great impact on student participation in online PAEL. 
Paper-Evaluation of Factors Affecting Student Participation in Peer-Assisted English Learning..

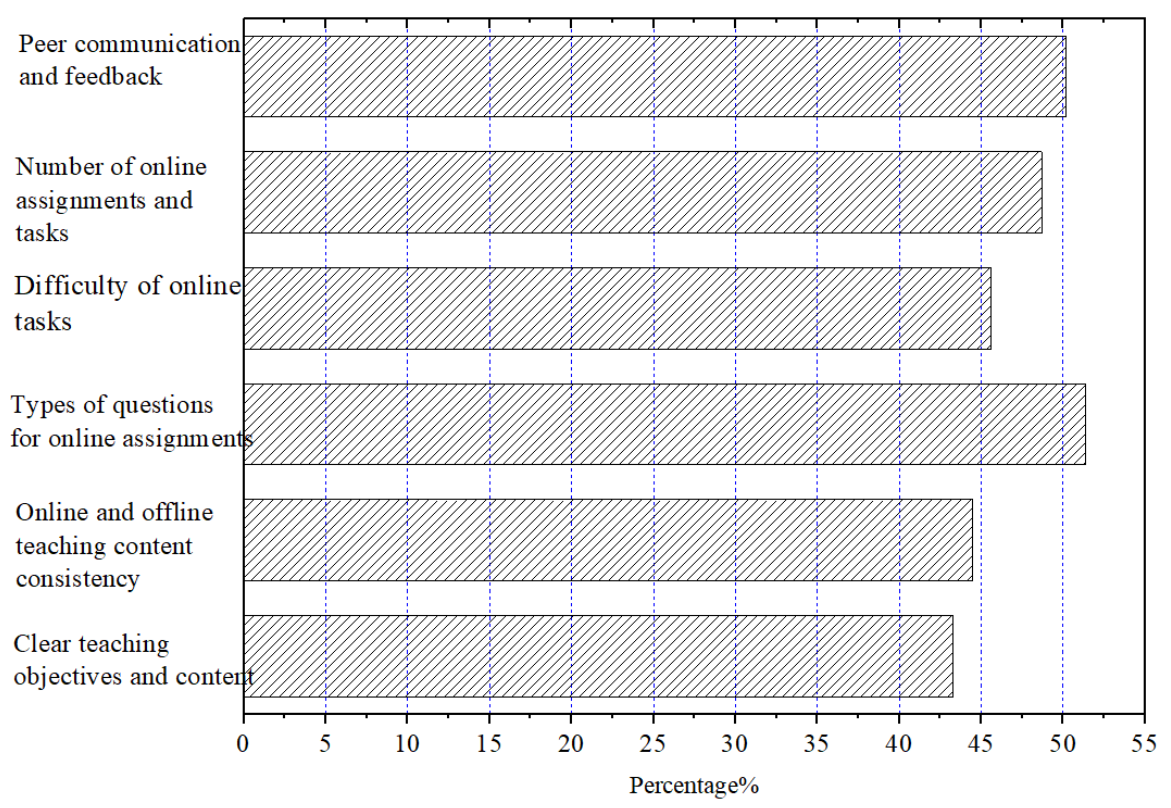

Fig. 11. Influence of teaching content on student participation in online PAEL

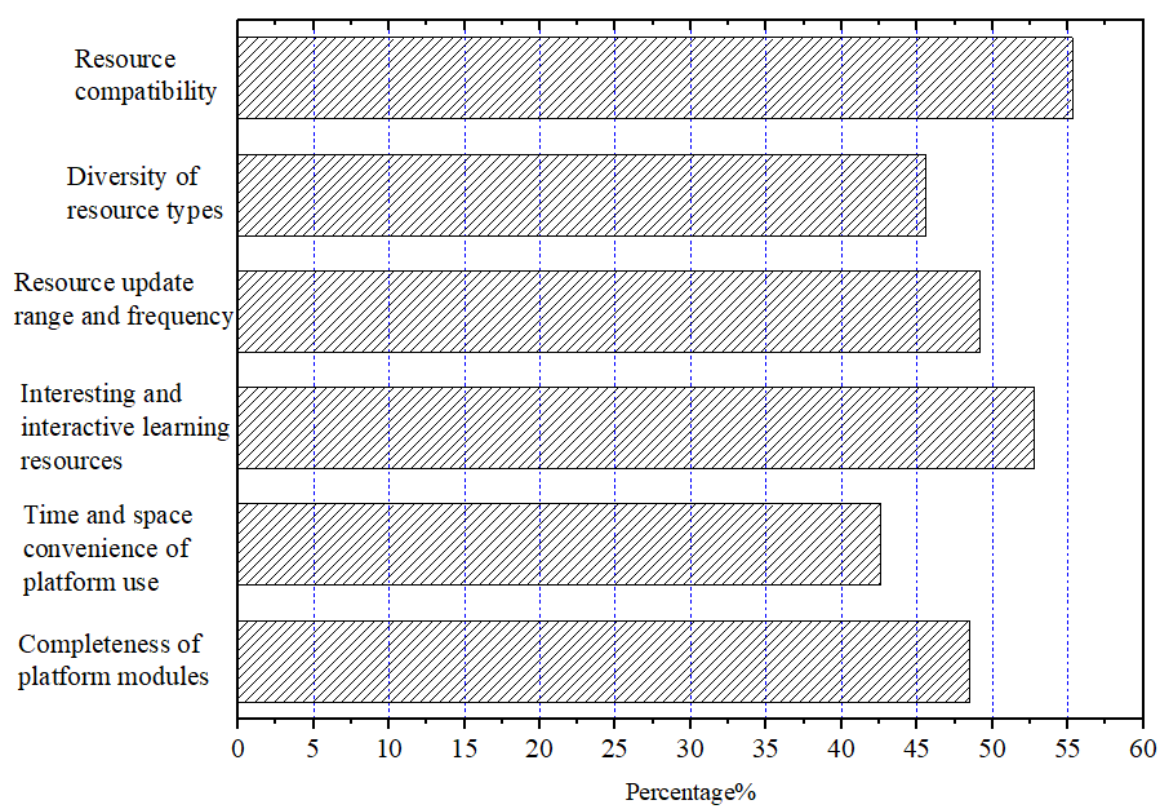

Fig. 12. Influence of online education platforms on student participation in online PAEL 


\subsection{Problems and countermeasures for student participation in online PAEL}

\section{Problems}

Through the above analysis, we have found three problems with student participation in online PAEL, namely:

i. Weak motives of students for online PAEL

The English subject has always been a headache for students. The difficult learning content and uselessness are the general reasons for their lack of interest in English learning. Besides, some students feel that online learning is not real enough, they have weak sense of knowledge gaining and the online learning takes up their spare time, therefore, students are interested in online PAEL; moreover, some students rarely take the initiative to conduct online learning since their self-learning ability is weak.

ii. Inadequate teaching design and supervision of teachers

The teaching contents prepared by teachers for online education platforms are mostly in the form of text, courseware, or videos; the teaching content is basically the same with the textbooks, there's nothing new nor interesting, therefore they can hardly attract students' attention. Meanwhile, teachers' supervision on students' online PAEL and homework completion is inadequate. Teachers invest few time and energy in students' PAEL and seldom participate in the discussion and exchange of students, and the teachers' feedbacks are always delayed, all these are reasons for students' low participation in online PEAL [16].

iii. Imperfect functions of online education platforms

Online education platforms are the main front for students to conduct PAEL, however, in the design of online education platforms, some functions are flawed, causing inconvenience for operations, such as the poor compatibility of platform resources, some content cannot be viewed on mobile phones and it has certain adverse influence on students' online PAEL; in addition, there're few extended content for English teaching and learning on the online education platforms, the contents on these platforms are mostly the contents of textbooks, teaching materials, and courses, which is not attractive to students and is not conducive to students' extended learning.

\section{Countermeasures}

Based on the survey results and data analysis of students' online PAEL situations, this paper proposed following suggestions and countermeasures for improving students' participation in online PAEL [17]:

\section{i. Students}

Students are the subjects of online PAEL activities; therefore, they must be fully aware that they are the dominant party in learning, they should improve their selflearning ability and self-management ability, make full use of the resources of online education platforms, conduct autonomous online learning, and use the platforms to 
interact with their peers, thereby forming a good learning atmosphere for mutual assistance.

\section{ii. Teachers}

First, teachers should carefully design the teaching content, provide comprehensive, rich and diverse teaching resources for students' online PAEL, reasonably arrange and design the teaching tasks, and stimulate students' interest in PAEL; second, teachers should formulate proper assessment standards for students' PAEL, strengthen supervision and assessment on students' online PAEL, urging students to perform online PAEL through supervision and assessment and cultivate good online PAEL habits; third, teachers should actively participate in students' online PAEL, offer technical supports, participate in the question discussion of students, and promote teacher-student and student-student PAEL.

iii. Online education platforms

When designing and upgrading online education platforms, platform designers and administrators should take the teachers' and students' PAEL requirements as the starting point, constantly improve the various functions of the platforms, create more real scenes for the knowledge and skill transfer of students, supply rich extended resources for teaching, set more interactive activities, thereby enhancing and enriching students' experience in online PAEL.

\section{Conclusion}

Student participation is a necessary condition for online learning. The quality and features of such interactive behavior between learners have a direct impact on learners' learning efficiency and their enthusiasm to participate in online learning. This paper conducted a research on the influencing factors of student participation in online PAEL and obtained the following conclusions:

1. This paper analyzed the interactive behavior of students' online PAEL based on online education platforms and the results showed that there're a few problems with student participation in online PAEL, namely the low-level knowledge structure and poor interaction quality, the weak intensity of interaction, and the inactive atmosphere of collaboration.

2. From the two aspects of surface participation and deep participation, this paper gave an overall evaluation to students' online PAEL and the results showed that overall situation of student participation is not satisfactory, both the surface participation and deep participation of students are not good.

3. The survey results on the influencing factors of student participation in online PAEL showed that teachers, students, teaching contents, and online education platforms all have great influence on student participation; the weak motives of students for online PAEL, the inadequate teaching design and supervision of teachers, and the imperfect functions of online education platform are all causes for the low participation of students in online PAEL; aiming at these problems, the paper proposed a few suggestions and countermeasures. 


\section{Acknowledgement}

This paper was supported by Key Project of Anhui Provincial Department of Education of China (SK2018A1144), Key Project of Anhui Provincial Department of Education of China (SK2019A0655), Anhui Provincial Quality Project (2020jyxm0346), Anhui Jianzhu University Quality Project (2019jy72).

\section{References}

[1] Leekitchwatana, P., Pimdee, P. (2020). An Analysis of Thai Student Teacher Appropriate Internet Use Behaviour, International Journal of Emerging Technologies in Learning, 16(2): 254-271. https://doi.org/10.3991/ijet.v16i02.13747

[2] Chen, X., Xia, E., Jia, W. (2020). Utilisation Status and User Satisfaction of Online Education Platforms, International Journal of Emerging Technologies in Learning, 15(19): 154-170. https://doi.org/10.3991/ijet.v15i19.17415

[3] Chan, C.K., Chan, Y.Y. (2011). Students' views of collaboration and online participation in Knowledge Forum. Computers \& Education, 57(1): 1445-1457. https://doi.org/10.1016/ j.compedu.2010.09.003

[4] Cheng, G., Chau, J. (2016). Exploring the relationships between learning styles, online participation, learning achievement and course satisfaction: an empirical study of a blended learning course. British Journal of Educational Technology, 47(2): 257-278. https://doi.org/10.1111/bjet.12243

[5] Dhar, J., Jodder, A.K. (2020). An effective recommendation system to forecast the best educational program using machine learning classification algorithms. Ingénierie des Systèmes d'Information, 25(5): 559-568. https://doi.org/10.18280/isi.250502

[6] Awidi, I.T., Paynter, M., Vujosevic, T. (2019). Facebook group in the learning design of a higher education course: an analysis of factors influencing positive learning experience for students. Computers \& Education, 129: 106-121. https://doi.org/10.1016/j.compedu.2018. $\underline{10.018}$

[7] Auvinen, T., Hakulinen, L., Malmi, L. (2015). Increasing students' awareness of their behavior in online learning environments with visualizations and achievement badges. IEEE Transactions on Learning Technologies, 8(3): 261-273. https://doi.org/10.1109/tlt.20 15.2441718

[8] Song, M., Sun, Z., Kai, L., Lang, X. (2015). Iterative 3d shape classification by online metric learning. Computer Aided Geometric Design, 35-36(C): 192-205. https://doi.org/10. 1016/j.cagd.2015.03.009

[9] Fernandez, J., Marin, R., Wirz, R. (2007). Online competitions: an open space to improve the learning process. IEEE Transactions on Industrial Electronics, 54(6): 3086-3093. https://doi.org/10.1109/tie.2007.907013

[10] Lin, H., Wei, Y. (2021). Design and implementation of college english multimedia aided teaching resources. International Journal of Electrical Engineering Education, 002072092098351. https://doi.org/10.1177/0020720920983517

[11] Sun, Z., Anbarasan, M., Kumar, D.P. (2020). Design of online intelligent English teaching platform based on artificial intelligence techniques. Computational Intelligence. https:// doi.org/10.1111/coin.12351 
[12] Jungblut, J., Vukasovic, M. (2013). And now for something completely different? Reexamining hybrid steering approaches in higher education. Higher Education Policy, 26(4): 447-461. https://doi.org/10.1057/hep.2013.28

[13] Regtien, P., Halaj, M., Kureková, E., Gabko, P. (2007). Comet: a multimedia internetbased platform for education in measurement. Measurement, 40(2): 171-182. https://doi. org/10.1016/j.measurement.2006.07.013

[14] Chen, G., Jin, Y., Liang, W., Liu, Y. (2021). Study on the influence of middle school students' self-efficacy on the willingness to use online learning platform. International Journal of Electrical Engineering Education, 002072092098403. https://doi.org/10.1177/ $\underline{0020720920984030}$

[15] Huang, C.J., Liu, M.C., Chu, S.S., Cheng, C.L. (2007). An intelligent learning diagnosis system for web-based thematic learning platform. Computers \& Education, 48(4): 658679. https://doi.org/10.1016/j.compedu.2005.04.016

[16] Kim, Y., Hwang, E., Rho, S. (2018). Twitter news-in-education platform for social, collaborative, and flipped learning. The Journal of Supercomputing, 74: 3564-3582. https://doi.org/10.1007/s11227-016-1776-x

[17] Wang, P., Qiao, S. (2020). Emerging Applications of Blockchain Technology on a Virtual Platform for English Teaching and Learning. Wireless Communications and Mobile Computing. https://doi.org/10.1155/2020/6623466

\section{$7 \quad$ Authors}

Hong $\mathrm{Hu}$ is a master graduate from Anhui University and currently serving as a lecturer of English Language and literature at School of Foreign Languages, Anhui Jianzhu University. Her research interest is transdisciplinary and focuses on applied linguistics and pragmatics. She is actively pursuing achievement of application of online platform to second language acquisition, in particular, English language teaching and learning. Email: graduation_hu@163.com

Jian $\mathrm{Hu}$ is a $\mathrm{PhD}$ graduate from Fudan University and was involved in the Postdoc program in Nanjing University from 2004 to 2006. Now she is a professor of English linguistics at School of Foreign Studies and Dean of School of International Education, Anhui University. Her research interest is transdisciplinary and focuses on cognitive linguistics and applied linguistics. She has authored more than 50 academic articles and 2 books and won several awards in teaching. Email: hujianpost@126.com

Xiuli Wang is an Associate Professor at the School of Foreign Languages, Anhui Jianzhu University. Her research interests are in language acquisition and embodied cognition. Email: gogowangna@163.com

Yuhui Zhai is an Asscociate Professor of Anhui Jianzhu University and her research focus on higher education, English language teaching and comparative literature. She is actively pursuing the research on reform of online English teaching methods and application of smart technologies. Email: yuhuizhai@163.com

Article submitted 2021-03-15. Resubmitted 2021-04-22. Final acceptance 2021-04-23. Final version published as submitted by the authors. 